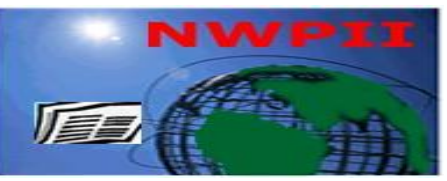

American Journal of Biomedical Sciences

ISSN: 1937-9080

nwpii.com/ajbms

\title{
Effects of extremely low frequency electromagnetic fields on kidney functions of albino rats in vivo study
}

\author{
Sahar E. Abo-Neima ${ }^{1 *}$, Hussein A. Motaweh ${ }^{1}$, Hassan M. Tourk ${ }^{1}$ and Marzoga F. Ragab ${ }^{2}$
}

${ }^{1}$ Department of physics, Faculty of Science, Damanhour University, Egypt.

${ }^{2}$ Department of physics, Faculty of Science, Omar El-Moktar University, ElgoubaLebya.

"Corresponding Author

Sahar E. Abo-Neima

Department of physics

Faculty of Science

Damanhour University Damanhour 2(045)

Egypt

E-mail: sahar_amr2002@yahoo.com

Received: 05 May 2016; | Revised: 21 October 2016; | Accepted: 27 October 2016

\begin{abstract}
In the present study fifty male albino rats were equally divided into three groups namely $\mathrm{A}, \mathrm{B}$ and $\mathrm{C}$, group $A$ used as control group, groups $B$ and $C$ were divided into two subgroups namely $B_{1}, B_{2}$ and $C_{1}, C_{2}$ respectively. $B_{1} \& C_{1}$ were exposed to $50 \mathrm{~Hz}, 3 \mathrm{KV} / \mathrm{m}$ electric field $(\mathrm{EF})$ for the periods of 15,30 days respectively; $\mathrm{B}_{2} \& \mathrm{C}_{2}$ were housed at normal environmental conditions for the periods of 15,30 days respectively. Fresh samples of kidney and blood were collected for experimental investigations. The dielectric constant $(\dot{\varepsilon})$ and electrical conductivity $(\sigma)$ were measured to investigate any changes in kidney structure. Kidney function was studied through analysis of urea \& creatinine after exposure to EF. The results show high significant changes in the value of $\dot{\varepsilon}$ and $\sigma$ of kidney for all groups as compared with control. EF can induce significant increase in the levels of kidney profile creatinine \& urea, these variations were recovered during two weeks after stopping exposure but they did not return to its original control values. Kidney histological section showed abnormal configuration of renal tubules, congested blood vessel and degenerated renal tubules, necrosis, glomerular shrinkage, and increase in space between glomerulus and Bowman's capsule.
\end{abstract}

Keywords: electric field, histopathology, kidney function, dielectric constant, conductivity.

\section{Introduction}

Life on earth has evolved amidst a broad band of electromagnetic frequencies, which originate from the universe [1] and the environmental, artificial, microwave devices, wireless communication devices, wireless computers and surgical instruments have been increased 
dramatically by more than trillion times. Nowadays, exposure to non-ionizing electromagnetic fields (EMFs) has increased due to mobile handset and base station antenna. Electromagnetic waves penetrate the animal body and act on all organs altering the cell membrane potential and the distribution of ions and dipoles. These alterations may influence the biochemical processes in the cell [2]. EMFs produce energy which affects the tissues [3-4].

Humans beings are unavoidably exposed to ambiet EMFs generated from various electrical devices and from power transmission lines. All of the electronic equipment's that we use in our daily life without thinking how much we use or how often we use creates EMF [5]. The increasing use of the electric technology, electromagnetic fields especially the extremely low frequency electromagnetic fields (ELF-EMF) have become a part of the modern life. These fields are produced by all electric devices, including high energy sources like power lines and microwaves, but also found in low energy devices such as cell phones [6].

The principle that electric fields can provoke biological effects has been known since the middle of the 19 century. Currently, the biological possessions of ELF- EMFs have attracted attention of many researchers to not only establish the basic mechanisms of its interaction to living systems but also its potential of practical applications [7]. The influence of EMFs on biological systems has been attracting interests of more and more scientists during the past two decades. A great deal of research has been conducted and convincing evidence indicates that exposure to ELF-EMF can induce the alterations in living systems [8]. Several studies have been performed to verify direct effects exerted by ELF EMF on cell functions. In recent years histological and physiological studies have increased in the evaluation of the effects of EMFs on human health [1-9-10-11-12-13]. It was reported that extremely low frequency EMF induced tissue damage in different organs of the experimental animals [14-15].

EM hazarded was considered one of the most dangerous types of pollution[16]due to EMFs which affected the functions of cells of the body [17].The results of many different types of animal and human studies dealing with the biological effects of exposure to ELF-EMFs have consistently been both positive and negative [1418].In literature, various theories are described concerning the effect of EMF on living organisms through induction, resonance, and radical mechanisms [19-20] affecting cell signal transmission, structure of biological membranes and ion transport, processes of replication and transcription of nucleic acids and synthesis of proteins, and cell proliferation processes [20]. The present study investigates the histopathological effects of permissible dose of EMFs on the kidney of albino rats. In exposed rat group to $50 \mathrm{~Hz}$ horizontal electric field for 8 hours/day for 8 weeks, many histological alterations such as focal tubular atrophy, necrosis and degeneration of the seminiferous epithelium were observed in the testes [21]. Zare et al [11] clarified that the exposed group of guinea pigs to $50 \mathrm{~Hz}$ electric field for 2 hours daily for 5days cause cytoplasmic vacuolations of the hepatocytes. Furthermore, swelling in the epithelial cells of renal tubules and subsequently cell necrosis were observed with glomerular dilatation. And also, atrophy of the seminiferous tubules was detected [11].

It was reported that ELF-EMFs induced tissue damage in different organs of the experimental animals [11-24]. Also, exposure to MF adversely affects spermatogenesis, Sertoli and Leydig cells of experimental animals [2526]. Recently, the histological and physiological studies have increased in the evaluation of the effects of EMFs on human health [11-13].

EMFs penetrate the human body and act on all organs altering the cell membrane potential and the distribution of ions and dipoles. These alterations may influence biochemical processes in the cell, thus, changing both biochemical parameters and enzyme activities of serum [127].

Creatinine is a chemical waste molecule that is generated from muscle metabolism. Creatinine is produced from creatine, a molecule of major importance for energy production in muscles. Approximately $2 \%$ of the body's creatine is converted to creatinine every day. Creatinine is transported through the bloodstream to the 
kidneys. The kidneys filter out most of the creatinine and dispose of it in the urine. Although it is a waste, creatinine serves a vital diagnostic function. Creatinine has been found to be a fairly reliable indicator of kidney function. As the kidneys become impaired the creatinine will rise. Abnormally high levels of creatinine thus warn of possible malfunction or failure of the kidneys [2829].

The aim of our work is to investigate the effects of electric field (EF) of strength $50 \mathrm{~Hz}-3 \mathrm{KV} / \mathrm{m}$ on possible histological changes, dielectric properties and kidney function tests in albino rats.

\section{Materials and Methods}

\subsection{Experimental animals and study design}

Animals kept in the same conditions for 2 weeks for adaptation. Experiments were performed on male rats weighing 170-200 gram; Animals presenting any symptoms of illness were excluded from the study. All testing was performed between 9:00 a.m. and 4:00 p.m. The experimental The animals were housed in the same environmental conditions in plastic cages, and feed with constant balanced diet and tap water which were equally divided into three groups namely $\mathrm{A}, \mathrm{B}$ and $\mathrm{C}$. Animals of group A are used as a control group and didn't receive any treatment and housed at normal environmental conditions the temperature inside the lab varied between $22^{\circ} \mathrm{C}$ and $25^{\circ} \mathrm{C}$, lighting condition are natural light from large windows during the day and complete darkness during the night. Animals of group B was divided into two subgroups namely $\mathrm{B}_{1}$ and $\mathrm{B}_{2}$ which were discretely exposed to $50 \mathrm{~Hz}, 3 \mathrm{kV} / \mathrm{m}$ electric field for a period of 15 day ( 8 hours/day, 5day/week). Group $\mathrm{B}_{2}$ animals were left to survive and housed at normal environmental conditions similar to control group A for a period of 15 day post exposed. Animals of group $\mathrm{C}$ are divided into two subgroups namely $\mathrm{C}_{1}$ and $\mathrm{C}_{2}$ were discretely exposed to the electric field for a period of 30 day ( 8 hours/day, 5day/week). Group $\mathrm{C}_{2}$ animals were left to survive and housed at normal environmental conditions similar to control group A for a period of 15 day post exposed. The device admit the rates to be under influence of an alternating electric field of $3 \mathrm{kV} / \mathrm{m}$. it is constructed of a plastic cuboid and its dimensions are $80 \mathrm{~cm}$ length, $20 \mathrm{~cm}$ width and $20 \mathrm{~cm}$ height. The two inner parallel sides of the cuboid covered by two isolated copper plates which are made of two PCB sheets. Fig.1. revealed the schematic diagram for exposure facility system the copper sheets are electrically connected with a power supply. The power supply consists of a variac and step up transformer. The alternating potential difference across the two plates was adapted to be 600 volts.

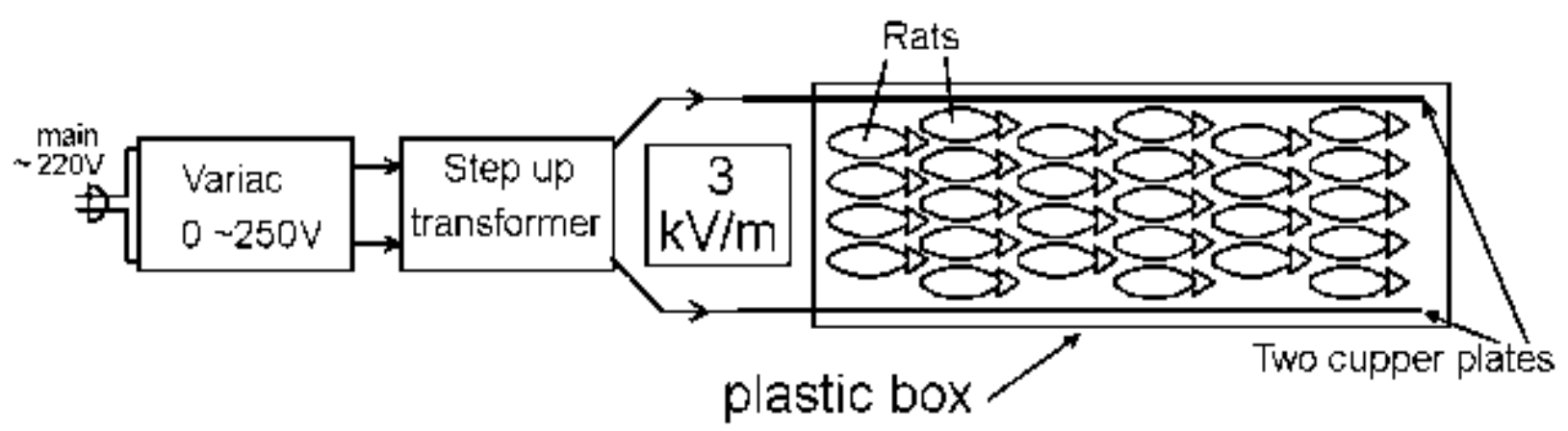

Figure 1. Schematic diagram for exposure facility system. 
Ethics

The experimental protocol was approved by the IV Local Ethics Committee for Animal Experimentation.

\section{Dielectric and conductivity measurements}

The dielectric measurements were carried out for the kidney samples in the frequency range $42 \mathrm{~Hz}-5 \mathrm{MHz}$ using a loss Factor Meter type HIOKI 3532 LCR Hi TESTER; version 1.02, Japan and cell types (PW 950/60) manufactured by Philips. Animals were sacrificed then the kidney was immediately excised and placed between a pair of $1 \mathrm{~cm}$ diameter black platinum circular electrodes for dielectric measurements, the sample between the electrodes was maintained at constant pressure, and the distance between the electrodes was measured through the use of a micrometer, while the kidney sample was filling the whole volume between the electrodes. During measurements, the sample between the electrodes was kept at a constant temperature of $24 \pm 0.1^{0} \mathrm{C}$ the capacitance $(\mathrm{C})$ of the tissue was measured at each frequency and the resistance $(\mathrm{R})$ was recorded each run was repeated three times.The relative permittivity $\varepsilon$ of the sample was calculated for each frequency using the relation:-

$$
\varepsilon^{\prime}=\frac{C d}{\varepsilon_{\mathrm{o}} A}
$$

Where $\mathrm{A}$ is the area of electrode, $\mathrm{d}$ the distance between the two electrodes, $\boldsymbol{\varepsilon}_{\mathbf{0}}$ is the permittivity of free space and $\boldsymbol{\varepsilon}$ is the dielectric constant. The dielectric loss $\varepsilon^{\prime \prime}$ is calculated from the relation

$$
\varepsilon^{\prime \prime}=\frac{\varepsilon^{\prime}}{2 \pi R C}
$$

Where $\mathrm{f}$ is the applied frequency in Hertz, $\mathrm{R}$ and $\mathrm{C}$ are the resistance and capacitance of the sample at resonance and $\delta$ is the loss angle. The electric conductivity $\sigma$ is given by:

$$
\sigma=2 \pi \varepsilon^{\prime \prime} \varepsilon_{0}
$$

\subsection{Histopathologicaly examination for kidney}

Specimens of kidney tissues were taken from all groups and prepared for the histological and histopathological sections following Banchroft and Stevens work, 2006[30] [Banchroft and Stevens 2006]. They were excised, fixed in in $10 \%$ buffered formalin $(10 \mathrm{ml}$ formalin in $30 \mathrm{ml}$ normal saline or sterilized distilled water) embedded in paraffin blocks and sectioned. The tissues were subsequently dehydrated in upgraded concentrations of alcohol (70\% alcohol) cleansed in xylene. Several sections of 3-6 micrometer thickness were cut, dried with blotting paper [31], using microtome then embedded in paraffin and sections stained with Hematoxylin and Eosin (H\&E) [32-33]. The slides were then evaluated for pathological changes under light microscope (100x). Photographs were taken using Kodak digital 10.3 mega pixels camera [34].

\section{Results \& Discussion}

In the present work, ELF-EMFs was chosen because it has been encountered in many work places, medical practice and new technologies in use nowadays [35] .The exposure of rats to electric fields can induce significant increase in the levels of kidney profile creatinine and decreased in urea as shown in Fig.2 for all groups as compared with control group A, Urea is the major nitrogen-contain in metabolic product of protein catabolism. The significant reduction in serum urea concentration throughout the experimental period may be attributed to impairment of the urea cycle leading to reduced production of the metabolic product. Since biosynthesis of urea could be divided into four stages of transamination, oxidative deamination of glutamate, ammonia transport and reactions of the urea cycle the increased in creatinine is an indication of partial loss of its functional capacity of tubular excretion. 


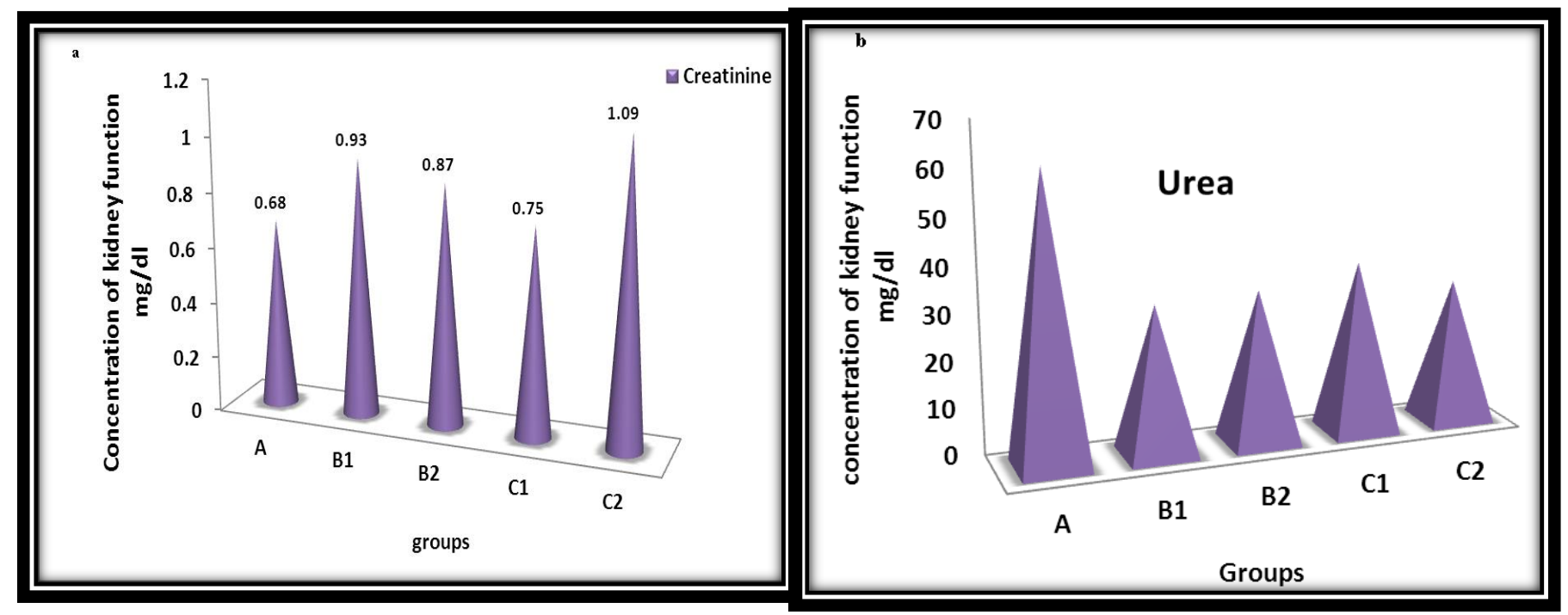

Figure 2.Effect of electric field on kidney functions of male rats (a) creatinine (b) Urea.

The dielectric relaxation spectroscopy study showed a dielectric dispersion in the frequency region from $42 \mathrm{KHz}$ to $5 \mathrm{MHz}$ for both control and exposed groups to $50 \mathrm{~Hz}-3 \mathrm{KV} / \mathrm{m}$ electric field. In this frequency range ( $\beta$-dispersion) the relaxation mechanism is due to the counter ion molecules and proteins at the cellular membrane. Fig.3,4\&5 illustrate the variation of the relative permittivity $\varepsilon$ , the dielectric loss $\tilde{\varepsilon}$ and the electric conductivity $\sigma$ for the kidney from groups $\mathrm{A}, \mathrm{B}_{1}, \mathrm{~B}_{2}, \mathrm{C}_{1}$ and $\mathrm{C}_{2}$ respectively, as measured in the range of $(42 \mathrm{KHz}-$ $5 \mathrm{MHz}$ ) to $50 \mathrm{~Hz}-3 \mathrm{KV} / \mathrm{m}$ electric field. The data indicated that there was a pronounced decrease in the dielectric loss for the sample except for group $B_{2}$ it attained a higher value than the control value as shown in Fig.4. The data also indicated that there was a pronounced decrease in conductivity of kidney tissue suspension with frequency for all groups as compared with control group as shown in Fig.5.It can also be noticed that the conductivity of group $\mathrm{B}_{2}$ was approximately returned to the control value this means that there is an improvement in the kidney state for recovery group.

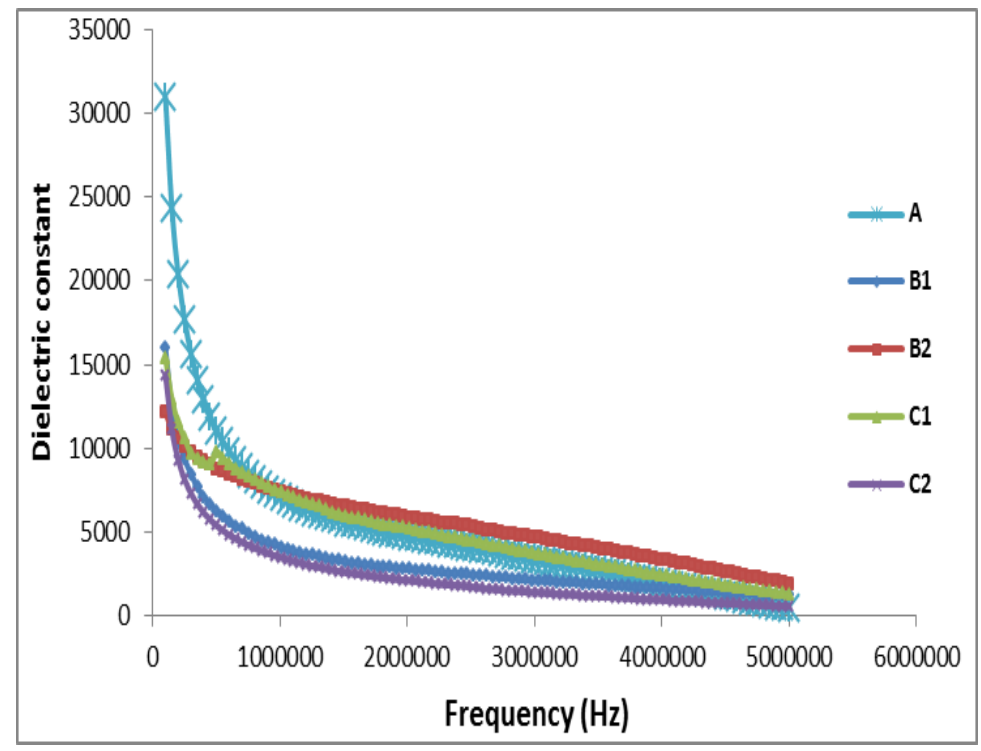

Figure 3. the variation of permittivity with frequency of the kidney tissue suspension after exposure to electric field and recovery values after two weeks. 


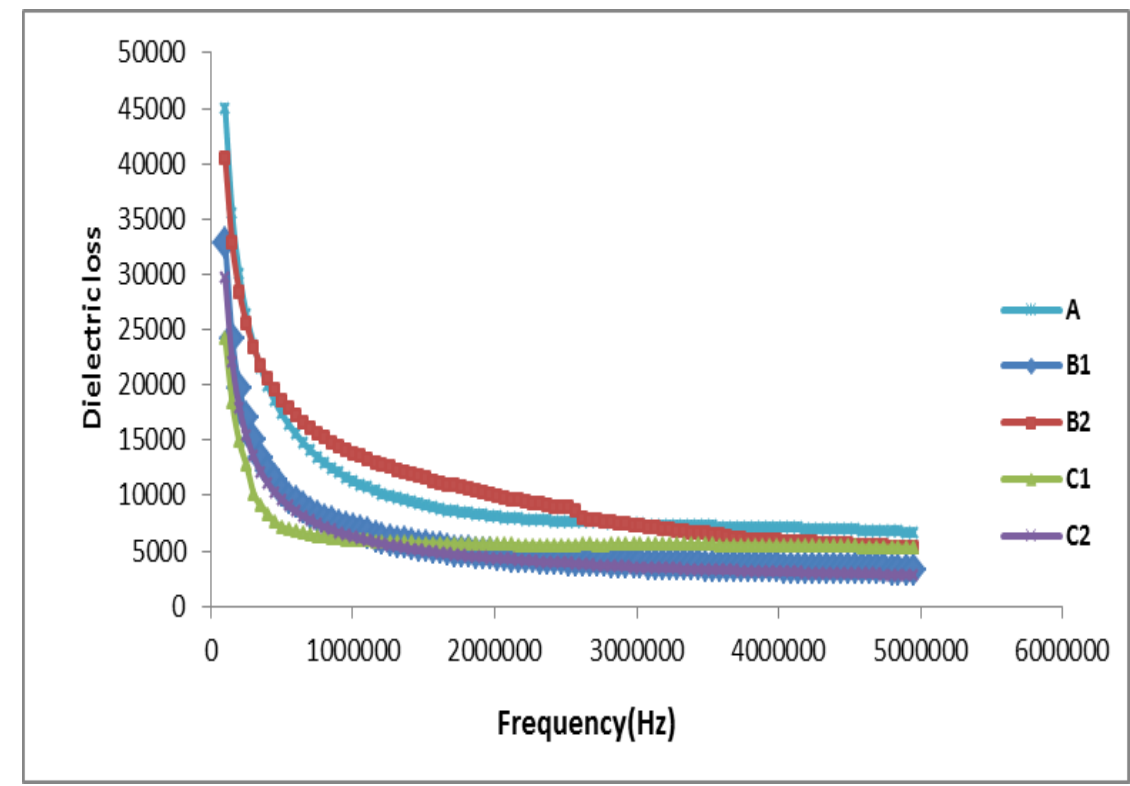

Figure 4. the variation of dielectric loss with frequency of the kidney tissue suspension after exposure to electric field and recovery values after two weeks.

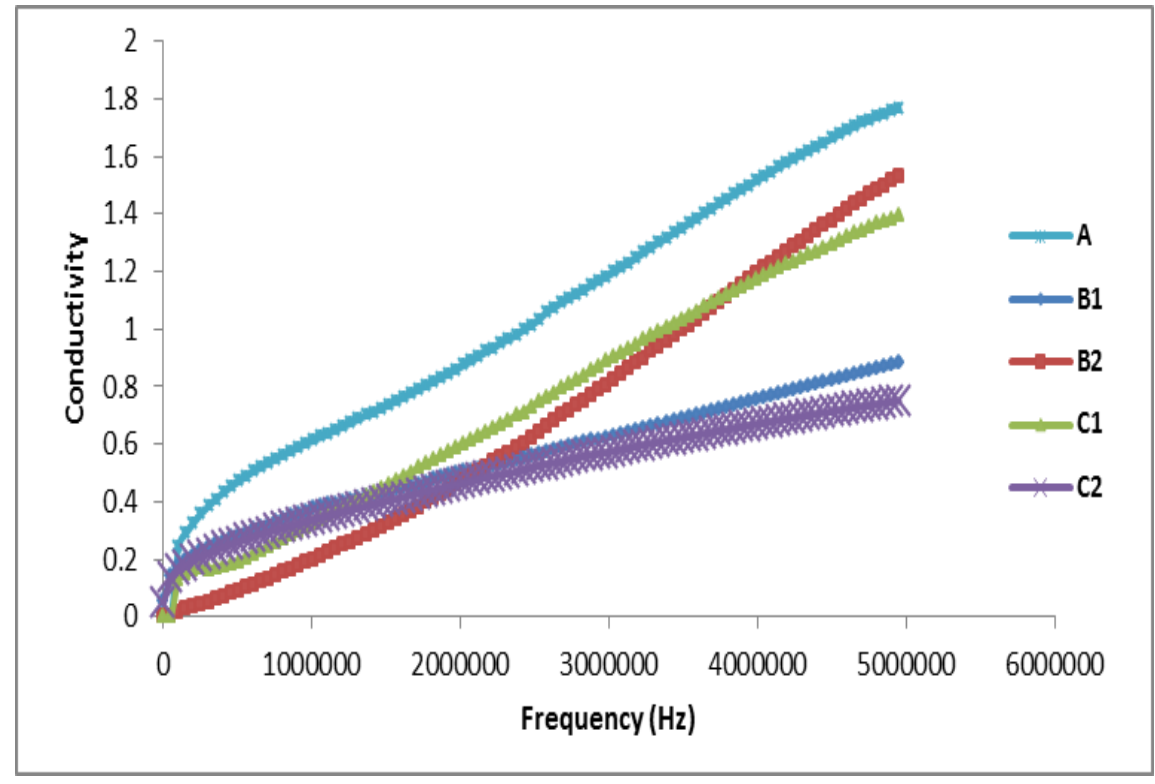

Figure 5. the variation of conductivity with frequency of the kidney tissue suspension after exposure to electric field and recovery values after two weeks post exposed.

Fig.6. revealed histological examinations of the kidney from the control group showed a normal appearance of glomeruli, renal tubules, and interstitial tissue. Fig.7. revealed histological examinations of the kidney of rats exposed to electric field for 15 days showing abnormal configuration of renal tubules RT(a) (H\&E×100). Showing congested blood vessel and degenerated renal tubules arrow (b) $(\mathrm{H} \& \mathrm{E} \times 400)$. Showing necrosis $\mathrm{N}$ and glomerular shrinkage GS, and increase in space between glomerulus and Bowman's capsule (c) (H\&E×400). Showing abnormal configuration of renal tubules arrow (d) (H\&E×100). Fig.8. indicates photo micrographs of kidney sections for group $\mathrm{B}_{2}$ (a) ME reveals shrunken glomeruli, abnormal configuration of renal tubules and increase in space between glomerulus and Bowman's capsule show arrow 
(H\&E×100) (b) $\mathrm{ME}$ reveals degenerated and lobulated glomeruli show arrow $(\mathrm{H} \& \mathrm{E} \times 400)$. (c and d) ME reveals abnormal configuration of renal tubules show arrow (H\&E×100). Fig.9. indicates photo micrographs of kidney sections for group $\mathrm{C}_{1}$ (a) $\mathrm{ME}$ reveals shrunken glomeruli , abnormal configuration of renal tubules and increase in space between glomerulus and Bowman's capsule show arrow $(\mathrm{H} \& \mathrm{E} \times 400)(\mathrm{b})$ ME reveals shrunken glomeruli, abnormal configuration of renal tubules and increase in space between glomerulus and Bowman's capsule show arrow (H\&E×400). (C and d) ME reveals abnormal configuration of renal tubules show arrow $(\mathrm{H} \& \mathrm{E} \times 100)$. Fig.10. indicates photo micrographs of kidney sections for group $\mathrm{C}_{2}$ (a) $\mathrm{ME}$ reveals shrunken glomeruli , abnormal configuration of renal tubules show arrow (H\&E×400) .(b, C and d) ME reveals abnormal configuration of renal tubules show arrow (H\&E×100).

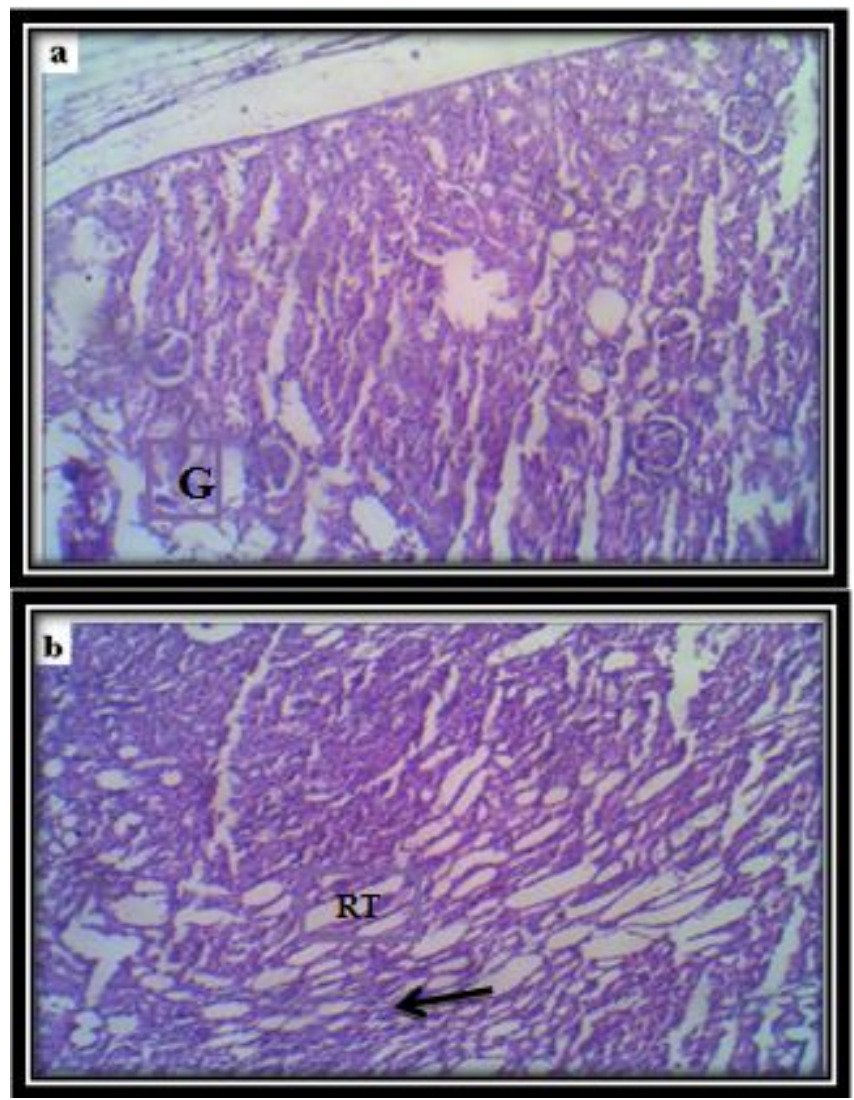

Figure 6. A section of the kidney of the control groups A $(\mathrm{H} \& \mathrm{E} \times 100)$.
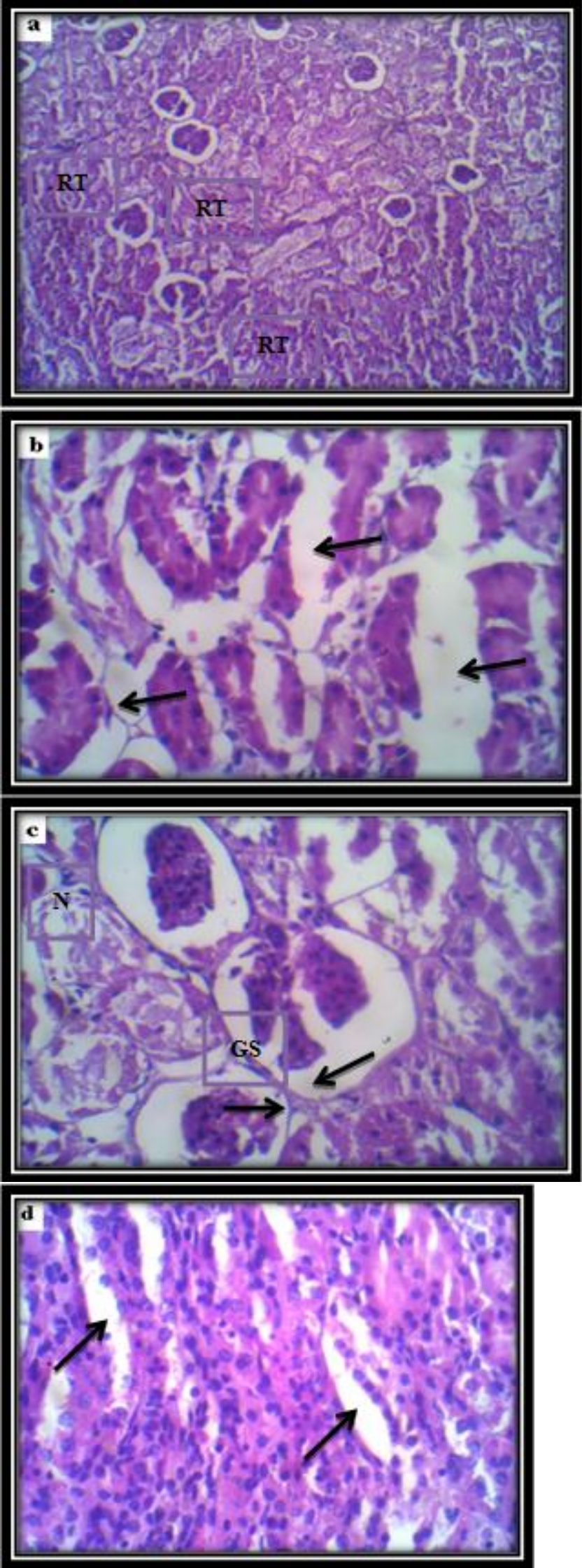

Figure 7. A section of the kidney of rats for group $\mathrm{B}_{1}$ showing abnormal configuration of renal tubules RT(a) $(\mathrm{H} \& \mathrm{E} \times 100)$. Showing 
congested blood vessel and degenerated renal tubules arrow (b)(H\&E×400). Showing necrosis $\mathrm{N}$ and glomerular shrinkage GS, and increase in space between glomerulus and Bowman's capsule (c) (H\&E×400). Showing abnormal configuration of renal tubules arrow (d) (H\&E×100).
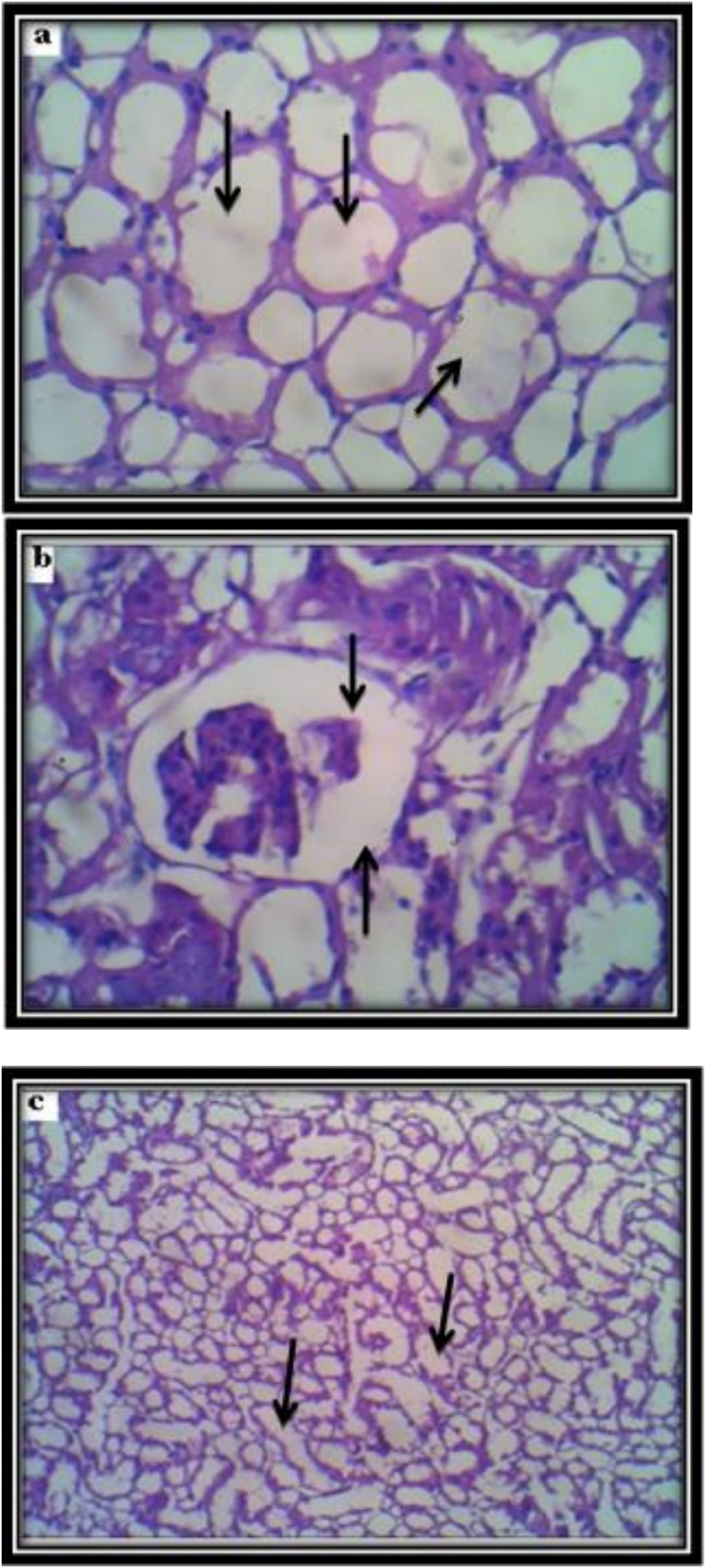

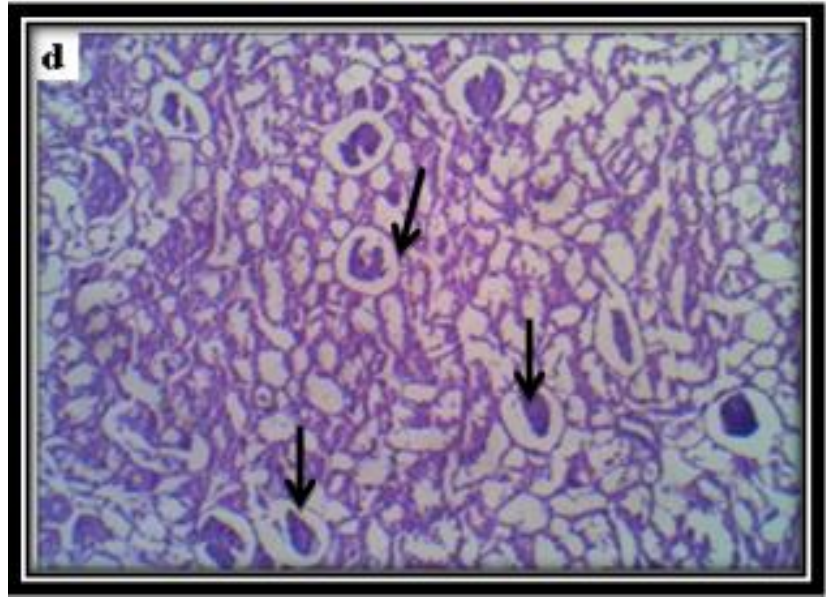

Figure 8: indicates photo micrographs of kidney sections for group $\mathrm{B}_{2}$ (a) $\mathrm{ME}$ reveals shrunken glomeruli,abnormal configuration of renal tubules and increase in space between glomerulus and Bowman's capsule show arrow $(\mathrm{H} \& \mathrm{E} \times 100)$ (b) ME reveals degenerated and lobulated glomeruli show arrow $(\mathrm{H} \& \mathrm{E} \times 400)$. (c and d) ME reveals abnormal configuration of renal tubules show arrow $(\mathrm{H} \& \mathrm{E} \times 100)$.
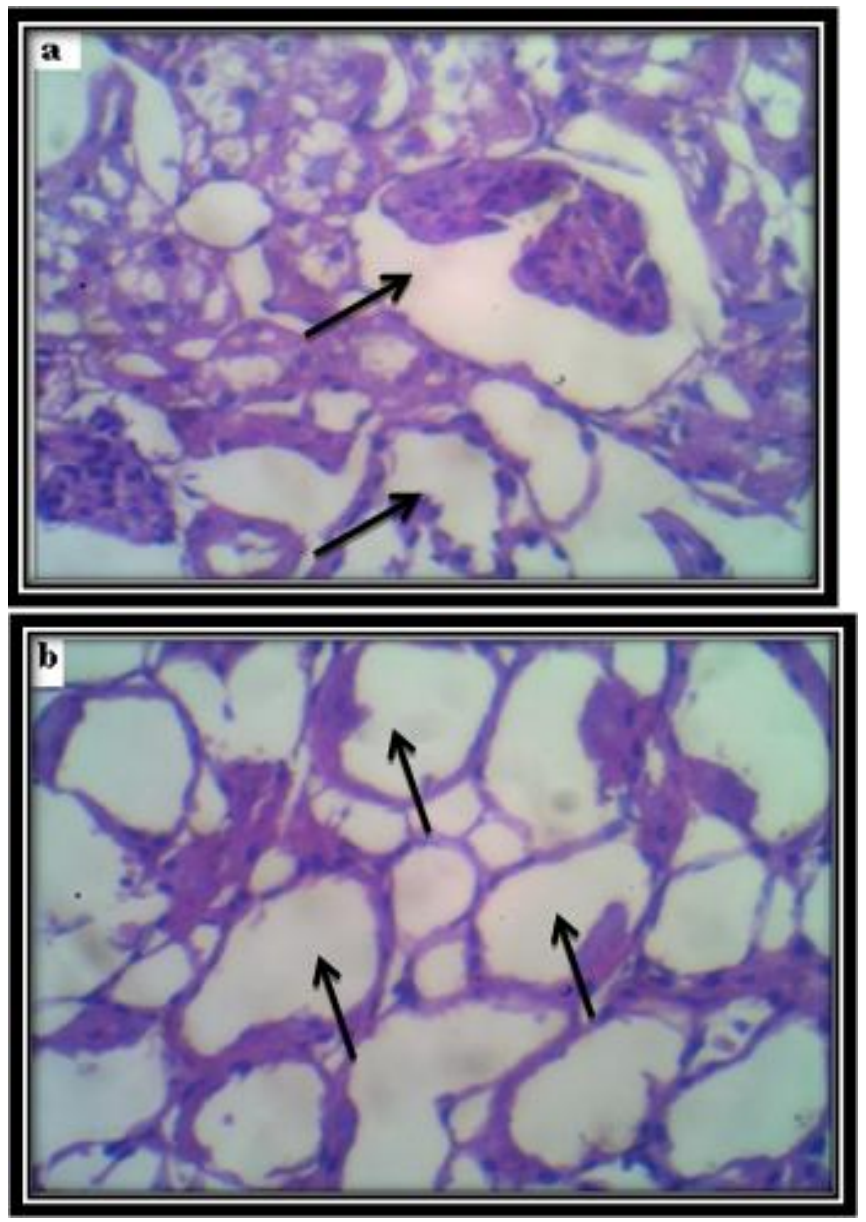

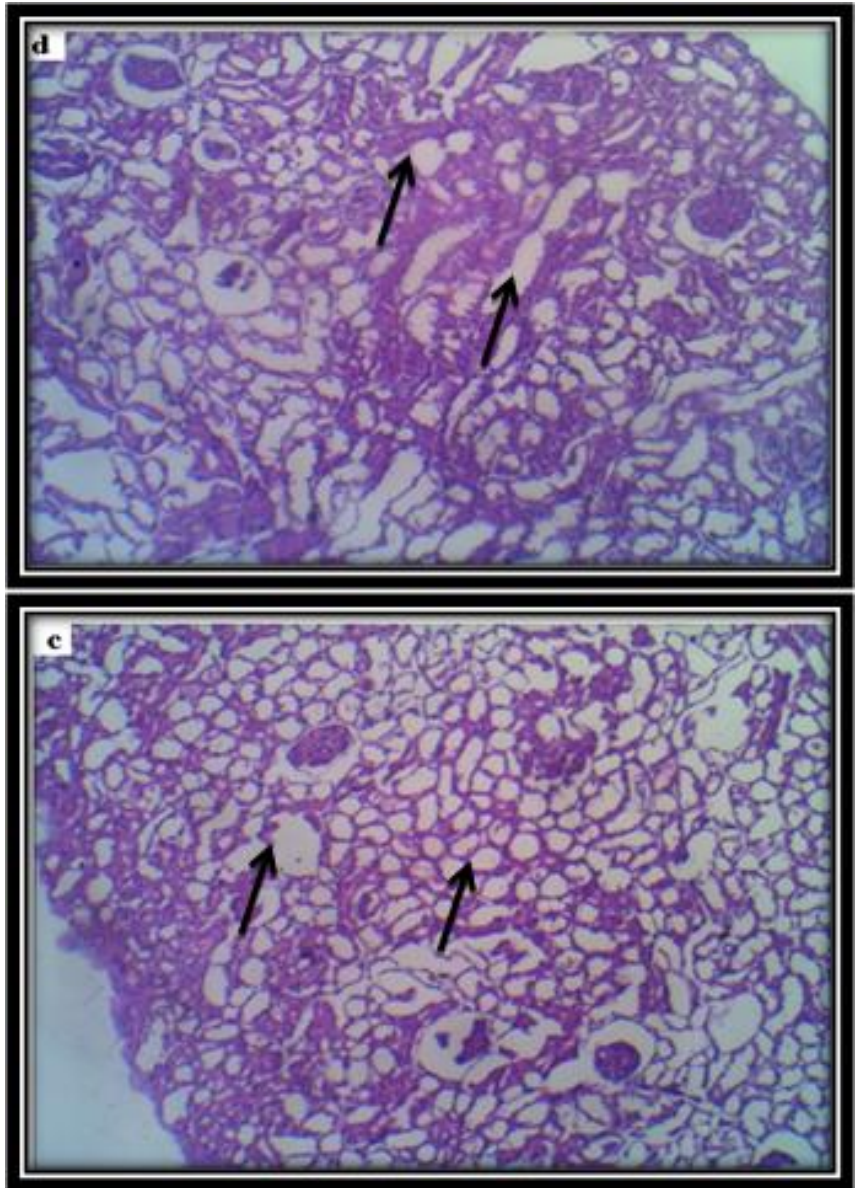

Figure 9: indicates photo micrographs of kidney sections for group $\mathrm{C}_{1}$ (a) $\mathrm{ME}$ reveals shrunken glomeruli , abnormal configuration of renal tubules and increase in space between glomerulus and Bowman's capsule show arrow $(\mathrm{H} \& \mathrm{E} \times 400)$ (b) ME reveals shrunken glomeruli, abnormal configuration of renal tubules and increase in space between glomerulus and Bowman's capsule show arrow $(\mathrm{H} \& \mathrm{E} \times 400)$. (C and d) ME reveals abnormal configuration of renal tubules show arrow $(\mathrm{H} \& \mathrm{E} \times 100)$.

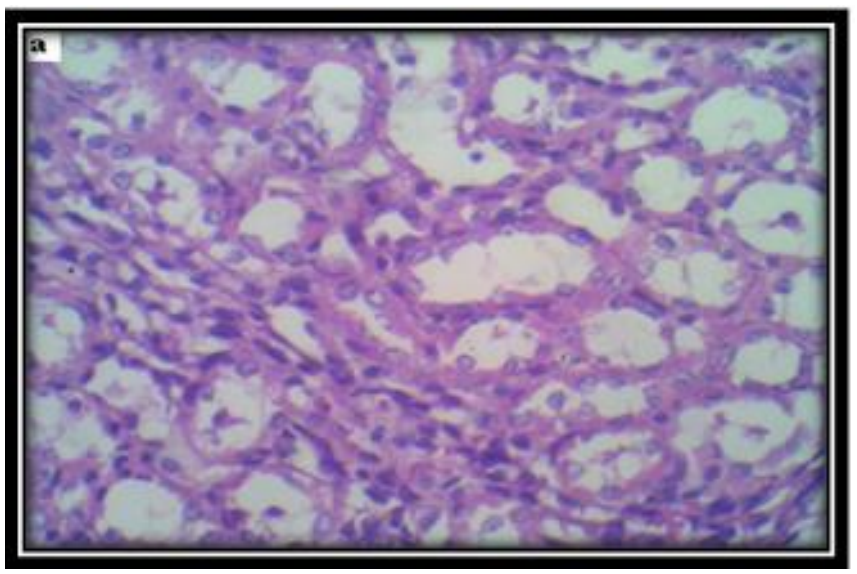

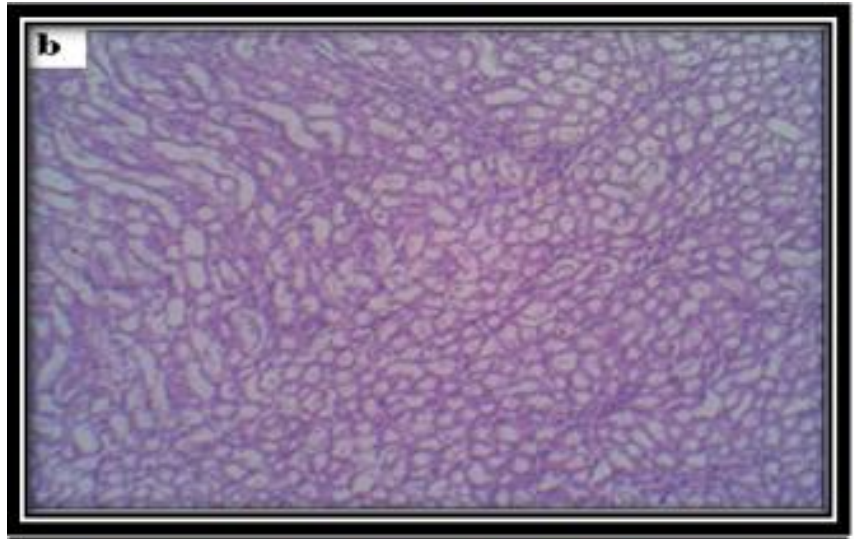
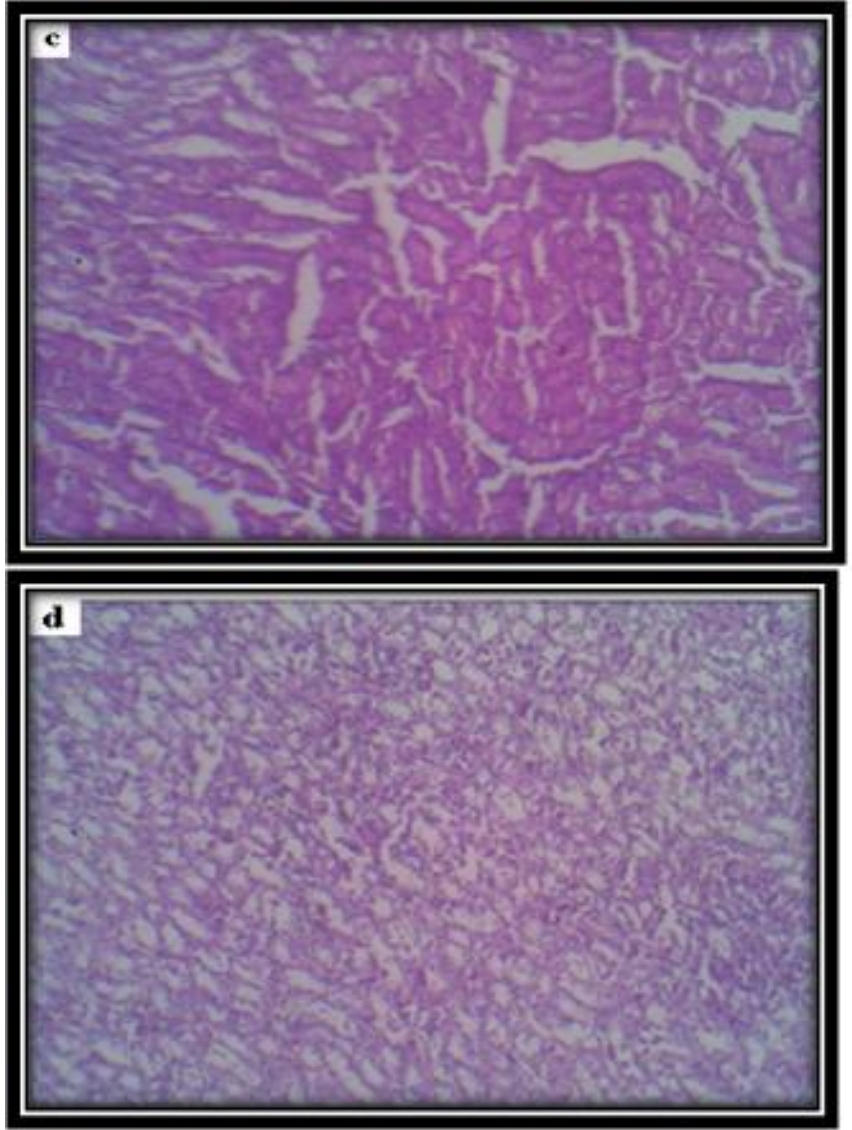

Figure 10: indicates photo micrographs of kidney sections for group $\mathrm{C}_{2}$ (a) $\mathrm{ME}$ reveals shrunken glomeruli, abnormal configuration of renal tubules show arrow (H\&E×400) .(b, $\mathrm{C}$ and d) $\mathrm{ME}$ reveals abnormal configuration of renal tubules show arrow $(\mathrm{H} \& \mathrm{E} \times 100)$.

The results of our study indicated that long term exposure to EF radiation increases serum creatinine level in male rats. The studies show that urea and creatinine significantly increase following increase in the duration of microwave exposure 
[36]. The adverse effects of waves have been shown on many tissues. The mobile phones emitting $900-\mathrm{MHz}$ electromagnetic radiation may be mainly absorbed by kidneys because they are often carried in belts [37], according to which, may influence serum creatinine level. Exposure to the electromagnetic radiation emitted is able to induce renal tissue damage [10]. The damage to such tissues may have a part in increasing of serum levels of creatinine. There is association between cell phone radiation and cellular damage [38], which in turn, may result in increased serum levels of creatinine.

\section{Conclusions}

1- In conclusion, the results demonstrated that Our findings show that long term exposure to electromagnetic radiations can increase serum creatinine level, according to which, may impose damaging health effects on body function.

2- It is necessary to review the dose limits recommended by the ICRP-60 for radiation workers based on the present findings.

3- This study suggests that, in humans under investigation, the activities of kidney function induce significant increase in the levels of kidney profile creatinine and urea; conductivity may decrease by exposure to electric field generated during magnetic resonance imaging or nuclear magnetic resonance procedures.

4- The decrease in conductivity due to field exposure and the recovery groups not returned to the control value during the recovery period this is an indicator that there is no improvement in the kidney state.

5- It is recommended not to allow buildings close or down to power-lines and a special protocol for buildings permission should be done in a way that exposures to such fields are omitted.

\section{References}

1. Lotfi SA. Effect of electromagnetic radiation emitted from a mobile phone station on biochemical and histological structure of some rat organs. Isotope \& $\operatorname{Rad}$. $\operatorname{Res}(2011)$; 43(1):95-103.

2. Lee J S, Ahn SS, Jung KC, Kirn YW\& Lee SK. Asian J. Androl (2004); 6(1): 29-34.

3. Hirata A, Watanabe $\mathrm{H} \&$ Shiozawa $\mathrm{T}$. Electromagn (2002) ; 44:592-594.

4. Lerchl A, Krüger $H$, Niehaus $M$, Streckert JR, Bitz AK\& Hansen V. J Pineal Res(2008) ; 44: 267-272. DOI: 10.1111/j.1600-079X.2007.00522.X

5. Ongel K, Gumral N, Ozguner F. The potential effects of electromagnetic field: A review (2009).

6. van Deventer TE, Saunders R, Repacholi $\mathrm{MH}$. WHO health risk assessment process for static fields. Prog Biophys Mol Biol (2005) ; 87: 355-363. DOI: 10.1016/j.pbiomolbio.2004.08.017

7. Martirosyan VN, Baghdasaryan \& AyrapetyanS. Bidirectional frequency dependent effect of extremely lowfrequency electromagnetic field on E.coliK-12.Electromagn.Biol.Med

(2013); 32(3):291-300. DOI: $10.3109 / 15368378.2012 .712587$

8. Zhang Y, Ding J, Duan W \& Fan W. Influence of Pulsed Electromagnetic Field with Different Pulse Duty Cycles on Neurite Outgrowth in PC12 Rat Pheochromocytoma Cells. Bioelectromagnetics(2005);26:406-411.

DOI: $10.1002 / \mathrm{bem} .20116$

9. Ozguner FI, Dindar H, Yagmurlu A, Savas C, Gokcora HI, Yucesan S. The effect of electromagnetic on undescended testis after orchiopexy. International Urology and Nephrology(2002) ; 33:87-93. DOI: 10.1023/A:1014473407519

10. Al-Glaib B, Al-Dardfi M, Al-Tuhami A, Elgenaidi A, Dkhil M. A technical report on the effect of electromagnetic radiation from a mobile phone on mice organs. Libyan Journal Medicine (2007) ; 1:8-9. 
11. Zare S, Alivandi S, Ebadi AG Histological studies of the low frequency electromagnetic fields effect on liver, testes and kidney in guinea pig. World Applied Sciences Journal (2007); 2(5):509-511.

12. Wang XW, Ding GR, Shi CH, Zhang J, Zeng LH, Guo GZ. (2008) Effect of electromagnetic pulse exposure on permeability of blood-testicle barrier in mice. Biomedical and Environmental Sciences (2008) ;21: 218-221. DOI: 10.1016/S08953988(08)60032-X

13. Hashem MA, El-Sharkawy NI Hematobiochemical and immunetoxicological effects of low electromagnetic field and its interaction with lead acetate in mice. Iraqi Journal of Veterinary Sciences (2009) ; 23: 105-114

14. Fiorani M, Biagiarelli B, Vetrano $\mathrm{F}$ et al (1997). In vitro effects of $50 \mathrm{~Hz}$ magnetic fields on oxidatively damaged rabbit red blood cells.Bioelectromagnetics(1997) ;18: 25-131. DOI: $10.1002 /(\mathrm{SICI}) 1521-$ $186 \mathrm{X}(1997) 18: 2<125::$ AID-

BEM5>3.0.CO;2-4

15. Khaki AA, Choudhry R, Kaul JK, Minaii B, Baybordi A, Oskuii G, Kafshnouchi M, Khaki AA, Tubbs RS, Shoja MM, Rad JS, Khaki A, Farahani RM, Zarrintan S, Nag TC.The effect of an electromagnetic field on the boundary tissue of the seminiferous tubules of the rat: A light and transmission electron microscope study. Folia Morphologica(2006) ; 65(3):188-194

16. Dilek UC, BeranY, Mehmet ZA, Cemil S \& Nuriye M. Alterations of Hematological Variations in Rats Exposed to Extremely Low Frequency Magnetic Fields $(50 \mathrm{~Hz})$ Archives of Medical Research (2009) ;40:352-356.

DOI: 10.1016/j.arcmed.2009.07.001

17. Al-Rajhi ME.Valuation of the Risks of Very Low Frequency and Non-Ionizing Electromagnetic Radiation Emitted by Electric Current of 50/60 Hz, Its Biological Effect, and Organization of Legislating Exposure Li-mites., Riyadh College of Technology, Riyadh (2006)
18. Varhney G, Katiyar V K\& Sushil K Effect of Magnetic Field on the Blood Flow in Artery Having Mul-tiple Stenosis: A Numerical Study. International Journal of Engineering, Science and Technology. (2012) ;2(2):67-82.

19. Sieroń A Application of magnetic fields in medicine. Medica Press, BielskoBiała, oland (2000).

20. Teresa B, Monika S,Kaarzyna J\& Ewa W.Effects of electromagnetic field on tissues of the oral cavity of rats a preliminary study. Bull Vet Inst Pulawy (2010) ; 54: 683-685

21. Erpeki S, Bilgin MD, Dikicioglu E, Karul A.The effects of low frequency electric field in rat testis. Revue Méd Vét (2007) ;158: 206-212.

22. Khayyat L,Abou-Zaid D. The effect of isothermal nonionizing electromagnetic field on the liver of mice. Egyptian Journal of Experimental Biology(Zoology) (2009) ;5:93-99.

23. Forgacs Z, Kubinyi G, Sinay H, Bakos $\mathrm{J}$, et al. Effects of whole-body $50-\mathrm{Hz}$ magnetic field exposure on mouse Leydig cells. Scientific World Journal 4 Suppl (2004) ; 2: 83-90.

24. Aydin M, Turk G, Yuksel M, Cevik A, Apaydin A, et al. Effect of electromagnetic field on the sperm characteristics and histopathological status of testis in rats. Medycyna Weterynaryjna (2007); 63:178183

25. Kula B. The Electric Field Effect on the Living Organisms, Part II,(1991); 39:713.

26. Price CP, Newall RG, Boyd JC. Use of protein: Creatinine ratio measurements on random urine samples for prediction of significant proteinuria: A systematic review. Clin Chem (2005);51:1577-1586. DOI: 10.1373/clinchem.2005.049742

27. Patel SS, Molnar MZ, Tayek JA, Ix JH, Noori $\mathrm{N}$, Benner D, Heymsfield S, Kopple JD, Kovesdy CP, Kalantar-Zadeh K.J Serum creatinine as a marker of muscle mass in chronic kidney disease: results of a 
cross-sectional study and review of literature. Cachexia Sarcopenia Muscle. (2013) ; 4(1):19-29. DOI: $\underline{10.1007 / s 13539-}$ 012-0079-1

28. Bancroft J.D\& Stevens Theory and Practice of Histological Techniques. Queens Medical Center, Notingham, University Hospital NHS Fourth Edition (2006).

29. Chauhan RS Veterinary laboratory diagnosis, $1^{\text {st }}$ ed, International book distributing Co., Lucknow, (2004) ; 269285.

30. Nawras KM (2011) The pathogenesis of experimental infection by Staphylococcus aureus in rabbits ,Kufa Journal For Veterinary Medical Sciences (2011) ; 2 (2): 127-140.

31. Maisa MA. Effect of aging on heart and ileum histology of male albino rats, Arch. Appl. Sci. Res (2012) ; 4 (3): 1345-1352

32. Sagan LA. Epidemiological and laboratory studies of power frequency electric and magnetic fields. J. Am. Med. Assoc (1992)
;268:625-629.

DOI:

10.1001/jama.1992.03490050073029

33. Juutilainen J.Effects of low frequency magnetic fields on embryonic development and pregnancy, Scand, J work Environ Health (1991) ; 17:147158. DOI: $10.5271 /$ sjweh. 1716

34. Moussa, SA.Oxidative stress in rats exposed to microwave radiation, Romanian J. Biophys (2009); 19:149158

35. Oktem F, Ozguner F, Mollaoglu H, Koyu A, Uz E. Oxidative damage in the kidney induced by $900-\mathrm{MHz}$-emitted mobile phone: Protection by melatonin. Arch Med Res (2005) ;36(4): 350-355. DOI: $10.1016 /$ j.arcmed.2005.03.021

36. Grundler W, Kaiser F, Keilmann F \& Walleczek J Mechanisms of electromagnetic interaction with cellular systems. Naturwissenschaften, (1992) ; 79:551-559. DOI: $\underline{\text { 10.1007/BF01131411 }}$ 